Research article

Open Access

\title{
Inflammatory mediators and cartilage biomarkers in synovial fluid after a single inflammatory insult: a longitudinal experimental study Janny $\mathrm{C}$ de Grauw ${ }^{1}$, Chris HA van de Lest ${ }^{2}$ and Paul René van Weeren ${ }^{1}$
}

\author{
${ }^{1}$ Department of Equine Sciences, Faculty of Veterinary Medicine, Utrecht University, Yalelaan 114, 3584 CM, Utrecht, The Netherlands \\ 2Department of Biochemistry and Cell Biology, Faculty of Veterinary Medicine, Utrecht University, Yalelaan 2, 3584 CM, Utrecht, The Netherlands \\ Corresponding author: Janny C de Grauw, j.c.degrauw@uu.nl
}

Received: 5 Dec 2008 Revisions requested: 18 Jan 2009 Revisions received: 16 Feb 2009 Accepted: 9 Mar 2009 Published: 9 Mar 2009

Arthritis Research \& Therapy 2009, 11:R35 (doi:10.1186/ar2640)

This article is online at: http://arthritis-research.com/content/11/2/R35

(C) 2009 de Grauw et al.; licensee BioMed Central Ltd.

This is an open access article distributed under the terms of the Creative Commons Attribution License (http://creativecommons.org/licenses/by/2.0), which permits unrestricted use, distribution, and reproduction in any medium, provided the original work is properly cited.

\begin{abstract}
Introduction Inflammation is an important feature of many joint diseases, and levels of cartilage biomarkers measured in synovial fluid may be influenced by local inflammatory status. Little is known about the magnitude and time course of inflammation-induced changes in cartilage tissue turnover as measured in vivo by synovial fluid markers. We aimed to study temporal changes in concentrations of inflammatory mediators, matrix metalloproteinase activity and cartilage biomarkers over 1 week in joints with experimentally induced inflammation.
\end{abstract}

Methods Localized inflammation was induced in the intercarpal joint of six horses by sterile injection of $0.5 \mathrm{ng}$ lipopolysaccharide, and synovial fluid was collected at postinjection hours $(\mathrm{PIH})$ 0, 8, 24 and 168. Concentrations of inflammatory mediators (prostaglandin $E_{2}$, substance $P$, and bradykinin), general matrix metalloproteinase activity and markers of collagen II turnover (CPII and $\mathrm{C} 2 \mathrm{C}$ ) as well as aggrecan turnover (CS846 and glycosaminoglycans) were measured with appropriate assays. One-way analysis of variance on repeated measures was used to analyze differences in synovial fluid marker levels over time.
Results Lipopolysaccharide-injection led to a sharp rise in prostaglandin $E_{2}$ at $\mathrm{PIH} 8$, while substance $P$, bradykinin and matrix metalloproteinase activity showed more sustained increases at PIH 8 and 24. Glycosaminoglycan release paralleled changes in the CS846 epitope, with an increase by $\mathrm{PIH}$ 8, a peak at PIH 24, and return to baseline by PIH 168. For type II collagen, a parallel time course between catabolic (C2C) and anabolic (CPII) markers was also observed, but the time course differed from that seen for proteoglycan markers:

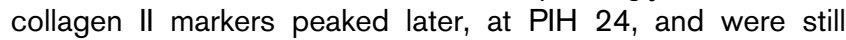
elevated over baseline at PIH 168.

Conclusions A primary intra-articular inflammatory insult, characterized by local release of peptide and lipid mediators and matrix metalloproteinase activation, can alter synovial fluid levels of proteoglycan biomarkers as early as 8 hours post-induction, and can lead to sustained rises in collagen II biomarkers during at least 1 week after onset.

\section{Introduction}

Inflammation is an important factor in the pathogenesis and clinical presentation of equine joint disease as well as human joint disease [1-3]. Overt joint inflammation as may be seen in rheumatoid arthritis or infectious arthritis is known to have devastating effects on the joint tissues, most importantly the articular cartilage, and in many joint disorders local release of catabolic mediators plays an important role in the disruption of cartilage matrix homeostasis [4].

Intra-articular inflammation can be studied in more detail by means of analysis of proinflammatory cytokines, inflammatory mediators and catabolic enzymes in synovial fluid (SF). Articular cartilage damage, whether inflammatory or traumatic in origin, can likewise be studied indirectly by means of SF

C2C: collagenase-cleavage neoepitope of type II collagen; CPII: carboxypropeptide of type II collagen; CS846: chondroitin sulfate epitope 846; ELISA: enzyme-linked immunosorbent assay; GAG: glycosaminoglycans; IL: interleukin; LPS: lipopolysaccharide; MMP: matrix metalloproteinase; $\mathrm{PIH}$ : post-injection hour; SF: synovial fluid; TNF: tumor necrosis factor. 
biomarkers of cartilage matrix turnover [5]. The extracellular matrix of articular cartilage is primarily made up of type II collagen and aggrecan. Biomarkers reflecting aggrecan as well as collagen II turnover have proven capable of signaling changes in cartilage matrix homeostasis in various disease states [510].

Of the many factors that may influence SF levels of cartilage turnover markers other than accumulated damage to the articular cartilage, local inflammation may be among the most important. Besides the potential dilution or washing-out of these markers due to joint effusion and/or altered clearance rates [11,12], there may be direct effects of inflammatory mediators and enzymes on articular cartilage turnover and thus on cartilage biomarker levels [13,14]. Few studies have so far attempted to quantify the effects of intra-articular inflammation on SF biomarker levels without the confounding effect of previous disease or concurrently created mechanical cartilage damage at baseline.

The horse is both a target animal for arthritis research and a suitable large animal model for the study of joint and cartilage disorders in humans [15-17]. In addition to having proportionately large joints from which ample SF can be obtained without the need for lavage or anesthesia [16], the horse is unique in that the pathophysiology of equine arthritis has been well studied for decades [18]. In horses, intra-articular lipopolysaccharide (LPS) injection in nanogram quantities is an established model for induction of transient localized sterile inflammation, which has been used to study clinical symptoms and gait parameters, drug pharmacokinetics, and/or the effects of therapeutic intervention [19-22].

The current study used this LPS model to investigate the influence of a single inflammatory insult on a panel of SF mediators and markers over the time course of 1 week. The panel included several inflammatory mediators and enzymes implicated in altered joint homeostasis in arthritic disease (prostaglandin $E_{2}$, substance $P$, bradykinin, matrix metalloproteinase (MMP) activity), as well as turnover markers of aggrecan (chondroitin sulfate epitope 846 (CS846) and glycosaminoglycans (GAG)) and collagen II (carboxypropeptide of type II collagen (CPII) and collagenase-cleavage neoepitope of type II collagen (C2C)). We found that lipid and peptide inflammatory mediators and MMP activity show an early rise within 8 hours of induction of inflammation, with concomitant transient increases in aggrecan turnover markers within the first 24 hours. Collagen II turnover markers showed a similar parallel time course between catabolic and anabolic markers, but their response was delayed (starting at 24 hours), and persisted 1 week after induction of inflammation.

\section{Materials and methods Experimental animals}

All experimental procedures and protocols were pre-approved by the Utrecht University Committee on the Care and Use of Experimental Animals in compliance with Dutch legislation on laboratory animal use. Six skeletally mature warmblood mares between 5 and 8 years of age with no history of orthopedic disease, free of lameness and with clinically and radiographically normal carpal joints were selected for this study. Horses were allowed a 2-week acclimatization period with once-daily hand-walking and were box-rested in separate $3.6 \times 3.6 \mathrm{~m}^{2}$ stalls on woodchip bedding for the duration of the experiment.

\section{Induction of inflammation}

At post-injection hour (PIH) 0, one randomly assigned carpus of each horse was clipped and prepared for dorsal arthrocentesis. Lipopolysaccharide from Escherichia coli O55:B5 (catalogue number L5418, lot 057K4106; Sigma-Aldrich, St Louis, MO, USA) was diluted to a final concentration of 0.625 $\mathrm{ng} / \mathrm{ml}$ in sterile lactated Ringer's solution. Horses were sedated with detomidine $(0.01 \mathrm{mg} / \mathrm{kg}$ intravenously, Domosedan ${ }^{\circledR}$; Pfizer, Capelle a/d IJssel, the Netherlands) and methadone $(0.1 \mathrm{mg} / \mathrm{kg}$ intravenously; Eurovet Animal Health, Bladel, the Netherlands). Arthrocentesis was performed with a $21 \mathrm{G}$ $\times 40 \mathrm{~mm}$ needle and $0.8 \mathrm{ml}$ LPS solution was delivered aseptically into the intercarpal joint after withdrawal of the PIH O SF sample.

\section{Assessment of clinical outcomes}

Before arthrocentesis at PIH 0, every 2 hours between PIH 2 and PIH 8, and at PIH 8, 24, 48 and 168, each horse's attitude, temperature, pulse and respiratory rate were recorded, lameness was scored on a standardized 0 to 5 scale [23], intercarpal joint effusion was graded on a scale from 0 to 4 as previously described [24], and carpal circumference was measured at the level of the accessory carpal bone with a tape measure. All scores were assigned and recorded by the same observer (JCdG).

\section{Collection of blood and synovial fluid}

Blood was collected from the left jugular vein for routine hematology before sedation for arthrocentesis at PIH 0, 8, 24 and 168. Part of each SF sample was placed in ethylenediamine tetraacetic acid tubes for macroscopic evaluation, routine SF total white blood cell count with differentiation and total protein measurement (refractometer), while the remainder was centrifuged in plain tubes at 13,000 rpm for 15 minutes, aliquotted and stored at $-80^{\circ} \mathrm{C}$ until further analysis.

\section{Synovial fluid mediator and marker analysis}

A total of eight assays were performed on each SF sample. The prostaglandin $E_{2}$ concentration was measured by a commercial ELISA (RnDsystems, Minneapolis, MN, USA) following RP-18 extraction of SF samples [25]. All peptide marker assays were performed in the presence of $1 \mathrm{mM}$ (final 
(a)

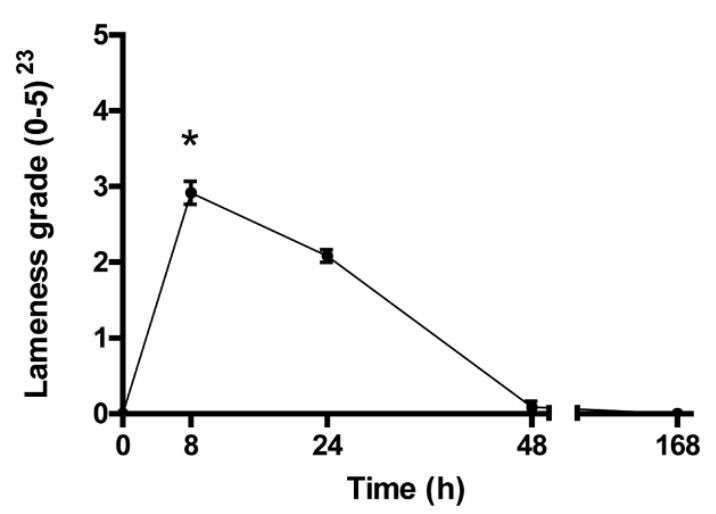

(b)

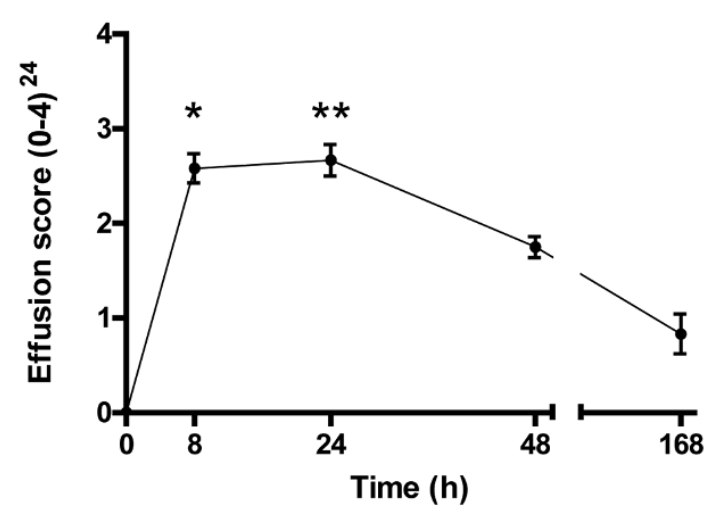

(c)

\section{Carpal circumference}

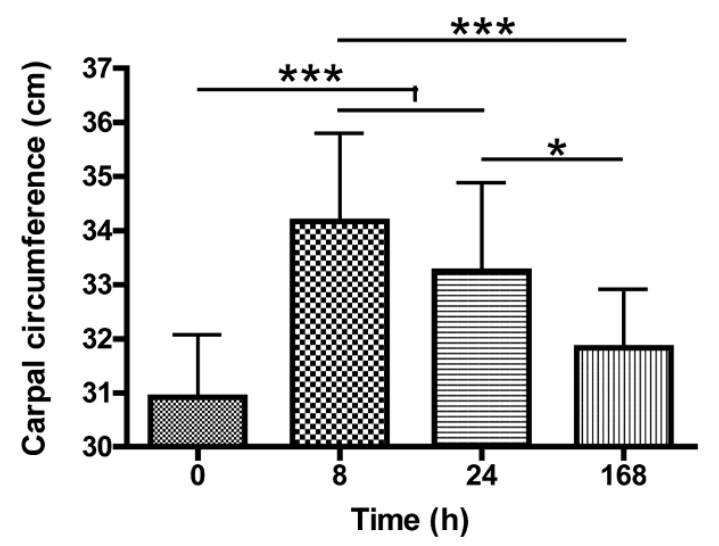

Clinical effects of lipopolysaccharide-induced joint inflammation. (a) Lameness grade, (b) effusion score and (c) carpal circumference following induction of synovitis in the intercarpal joints of horses $(\mathrm{n}=6)$. Inflammation was induced at $t=0$ by intra-articular injection of $0.5 \mathrm{ng}$ Escherichia coli lipopolysaccharide. Data presented as the mean \pm standard error of the mean. ${ }^{\star} P<0.05,{ }^{\star \star} P<0.01,{ }^{\star \star \star} P<0.001$ compared with baseline $(t=0)$.

concentration) phenylmethylsulphonylfluoride (an inhibitor of serine proteases). Substance $P$ and bradykinin were measured using commercial enzyme immunoassay kits (substance P kit from Cayman Chemical, Ann Arbor, MI, USA; and bradykinin kit from Bachem, Bubendorff, Switzerland).

General MMP activity was measured by means of a fluorimetric assay based on cleavage of the fluorogenic peptide substrate FS-6 (Calbiochem, San Diego, CA, USA). This substrate was previously shown to be considerably more sensitive than FS-1 for measuring activity of collagenases (MMP1, MMP8, MMP13) in biological fluids [26]. In short, to $20 \mu \mathrm{SF}$ were added $80 \mu \mathrm{l}$ MMP buffer $(0.1 \mathrm{M}$ Tris, $0.1 \mathrm{M} \mathrm{NaCl}, 10 \mathrm{mM}$ $\mathrm{CaCl}_{2}, 0.05 \%(\mathrm{w} / \mathrm{v})$ Triton X-100, 0.1\% (w/v) PEG6000, pH 7.5) and $100 \mu \mathrm{l}$ of $10 \mu \mathrm{M}$ FS-6 solution, after which the fluorescent signal was monitored for 10 minutes. The slope of the resultant linear curve (relative fluorescence units/second) was calculated as a measure of general MMP activity.
GAG release was quantified by the 1,9-dimethylmethyleneblue assay, adapted for use in microtiter plates [25]. Concentrations of the CS846 epitope (a putative marker of aggrecan synthesis $[27,28]$ ), as well as of CPII (a marker of type II collagen synthesis [29]) and C2C (a neoepitope present on collagenase-cleavage fragments of type II collagen [30,31]) were measured using commercial ELISA kits (IBEX, Montreal, Quebec, Canada). All of these assays were previously validated for use in the horse [25,32].

\section{Statistical analysis}

Data are presented as the mean \pm standard error of the mean. The effect of time after induction of inflammation on concentrations of SF parameters was tested by use of one-way analysis of variance on repeated measures. When a significant time effect was observed, levels at individual time points were compared with Tukey's post hoc tests. Categorical clinical variables were compared over time using a Friedman test, followed by Dunn's post hoc tests. Computer software was used 
Table 1

Results of conventional synovial fluid analysis following intra-articular injection of $\mathbf{0 . 5} \mathbf{n g}$ lipopolysaccharide

\begin{tabular}{|c|c|c|c|c|}
\hline & \multicolumn{4}{|c|}{ Time after lipopolysaccharide } \\
\hline & 0 hours & 8 hours & 24 hours & 168 hours \\
\hline Total protein (g/dl) & $1.27 \pm 0.18$ & $4.70^{\star} \pm 0.18$ & $4.80^{\star} \pm 0.14$ & $1.53 \pm 0.18$ \\
\hline Leucocytes (x109 cells/l) & $0.25 \pm 0.085$ & $215.4^{\star} \pm 15.9$ & $64.6^{*}, \pm 6.7$ & $0.72 \pm 0.38$ \\
\hline Neutrophils (\%) & $\mathrm{N} / \mathrm{A}$ & $98.8^{\star} \pm 0.31$ & $80.0^{*}, + \pm 3.4$ & $\mathrm{~N} / \mathrm{A}$ \\
\hline
\end{tabular}

Comparison of synovial fluid total protein, white blood cell counts and differentiation over time after induction of joint inflammation. Data correspond to the mean \pm standard error of the mean ( $n=6$ horses). N/A, no differentiation performed given low white blood cell counts. ${ }^{*}$ Significant difference from $\mathrm{PIH} O$ and $168(P<0.001)$. ${ }^{+}$Significant difference from $\mathrm{PIH} 8(P<0.001)$.

(GraphPad Prism version 4.00 for Windows; GraphPad Software, San Diego, CA, USA) and the level of significance was set at $P<0.05$.

\section{Results}

\section{Clinical assessment}

LPS injection led to a significant rise in lameness and effusion scores and carpal circumference (Figure 1). The lameness score was no longer significantly different from 0 at $\mathrm{PIH} 24$ and lameness had resolved by $\mathrm{PIH} 48$ in all six horses, while joint effusion showed a more gradual decline. No changes in appetite, pulse or respiration were observed, and rectal temperature and hematological variables remained within normal limits (data not shown).

\section{Conventional synovial fluid parameters}

The results of routine SF analyses are presented in Table 1.

\section{Synovial fluid mediators and markers}

Induction of inflammation led to a sharp rise in prostaglandin $E_{2}$ at PIH 8, while substance $P$, bradykinin and MMP activity showed more sustained increases at PIH 8 and 24 (Figure 2). GAG release and the CS846 epitope showed parallel changes after LPS injection. Both were already significantly elevated by $\mathrm{PIH}$ 8, peaked at $\mathrm{PIH} 24$, and returned to baseline levels by PIH 168 (Figure 3). For type II collagen, parallel profiles of putative catabolic (C2C) and anabolic (CPII) markers over time were also observed, but the time course differed from that seen for aggrecan markers in that collagen II markers rose later, at $\mathrm{PIH} \mathrm{24,} \mathrm{and} \mathrm{were} \mathrm{still} \mathrm{elevated} \mathrm{over} \mathrm{baseline} \mathrm{at}$ PIH 168 (Figure 4).

\section{Discussion}

Over the past decades, the importance of intra-articular inflammation in joint pain, joint effusion and progression of cartilage damage has become increasingly appreciated [2,33], as has the usefulness of synovial fluid biomarkers for monitoring disease progression or therapeutic response [5]. The magnitude and timing of the effects of active inflammation on SF biomarker levels, however - although acknowledged by many before - have received relatively little formal attention.
The inflammatory response elicited in the present study by intra-articular injection of $0.5 \mathrm{ng}$ LPS was overt but also highly transient, and the absence of systemic signs of endotoxemia confirmed the local nature of LPS effects. The clinical response to LPS and changes in routine SF parameters closely paralleled those documented previously [21,22], confirming reproducibility of this model for induction of severe but transient joint inflammation.

We further characterized the induced inflammatory response through SF analysis of inflammatory mediators and painrelated (neuro)peptides. The observed increase in prostaglan$\operatorname{din} E_{2}$ was sharp and short-lived, which agrees with previous studies [19,34]. The involvement of bradykinin and substance $P$ in this model is a novel finding; from studies on LPS-mediated effects in rodents, we hypothesized that LPS would indeed induce bradykinin and substance $P$ release $[35,36]$. Owing to the descriptive nature of the present study and the known interactions between prostaglandin $E_{2}$, substance $P$ and MMP activity, we cannot determine to what extent changes in cartilage markers were due to each individual mediator. The observed increases in these mediators, however, do implicate each of them in the synovial inflammatory process, and they all may have contributed to the accompanying changes in cartilage turnover markers. While prostaglandin $E_{2}$ and substance $P$ are known actors in cartilage degradation in arthritic joints [3,37], the effects of bradykinin on articular cartilage remain largely unknown [38]. Certainly, our findings warrant further investigation of the involvement of each of these mediators and their receptors in altered cartilage turnover in arthritis.

The rise in prostaglandin $E_{2}$, bradykinin and substance $P$ in the first 24 hours coincided with an increase in MMP activity at $\mathrm{PIH} 8$ and 24. The fluorogenic substrate used shows enhanced sensitivity for collagenase-mediated (MMP1, MMP8, MMP13) cleavage, but may also be cleaved by TNF $\alpha$ converting enzyme [26]. Unfortunately, activity assays that utilize capture antibodies for specific MMP subtypes have not yet been developed for use in the horse, so no inferences regarding activities of individual MMPs are justified. 


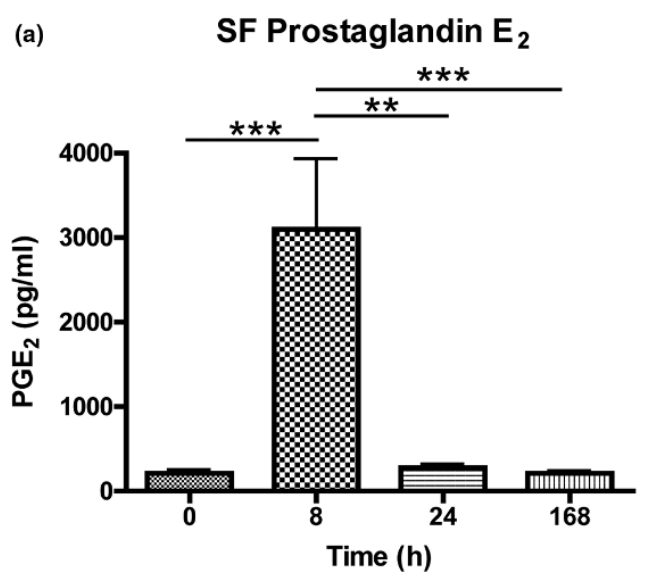

(c)

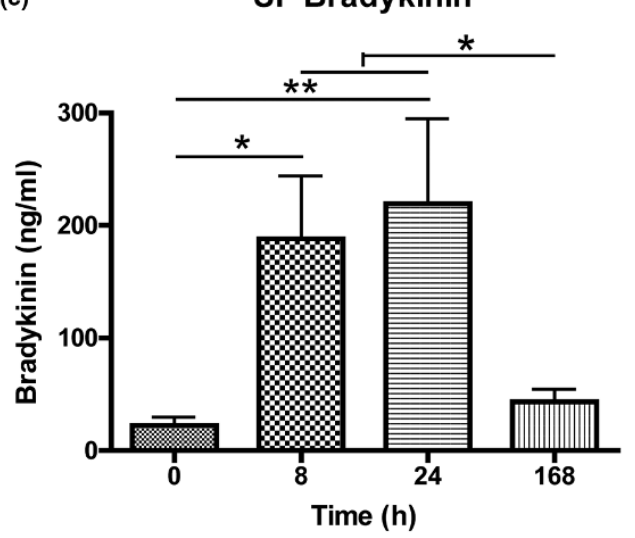

(b)

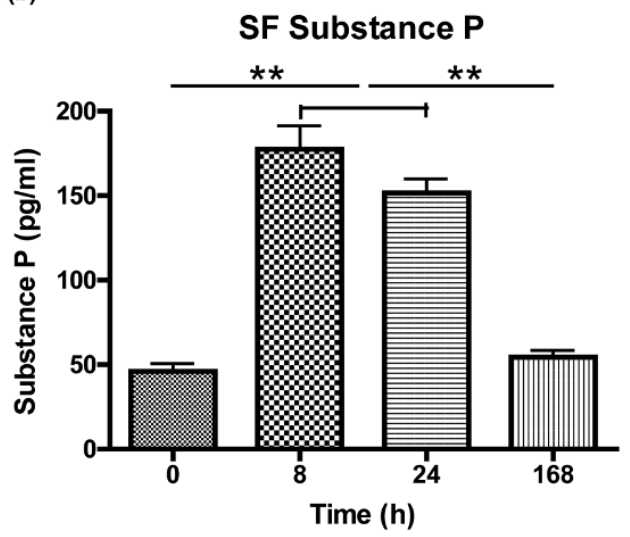

(d)

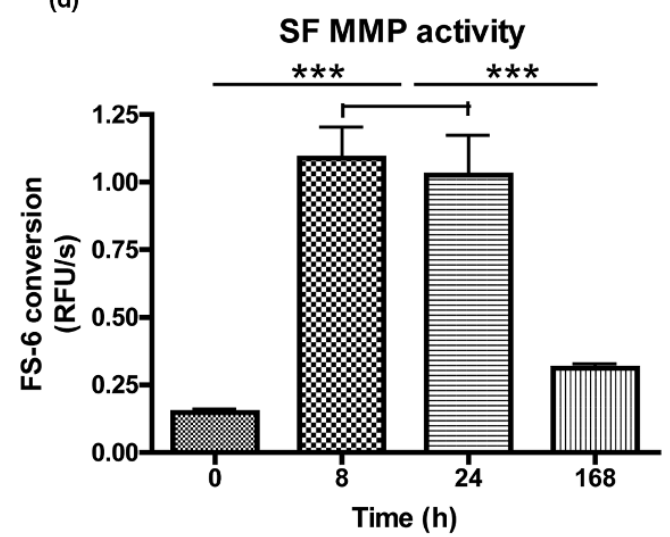

Synovial fluid inflammatory mediators and matrix metalloproteinase activity in inflamed joints. Synovial fluid (SF) levels of (a) prostaglandin $E_{2}\left(P G E_{2}\right)$, (b) substance $\mathrm{P},(\mathbf{c})$ bradykinin, and (d) general matrix metalloproteinase (MMP) activity over time in inflamed intercarpal joints of horses $(n=6)$. Inflammation was induced at $t=0$ by intra-articular injection of $0.5 \mathrm{ng}$ Escherichia coli lipopolysaccharide. Data presented as the mean \pm standard error of the mean. ${ }^{\star} P<0.05,{ }^{\star \star} P<0.01,{ }^{\star \star \star} P<0.001$. RFU/s, relative fluorescence units/second.

LPS injection resulted in a swift and transient response of aggrecan turnover markers, both CS846 epitope and GAG release rising within 8 hours of LPS injection and returning to baseline after 1 week. This agrees with previously documented early increases in the release of aggrecan fragments from cartilage in response to injury or inflammatory stimuli $[39,40]$. Concentrations of the CS846 epitope in synovial fluid, proposed to reflect the turnover of novel aggrecan molecules $[27,28]$, showed a strikingly similar time course to GAG levels following induction of inflammation. As both markers returned to baseline within 1 week, this inflammation-induced enhancement of aggrecan turnover seems to be both a fast and short-lived phenomenon.

A parallel course like that seen for aggrecan turnover markers was also evident for collagen II; however, the response of collagen II markers to LPS injection was delayed (at PIH 24) and persisted longer, with levels of both anabolic (CPII) and cata- bolic (C2C) markers still being elevated over baseline at $\mathrm{PIH}$ 168. This time lag between changes in aggrecan and collagen II markers in SF coincides with that seen in cartilage extracts in the rat mono-iodoacetate model of arthritis [41]. Concomitant with a rise in $\mathrm{C} 2 \mathrm{C}$ at $\mathrm{PIH} 24$ and 168, indicating inflammation-induced enhancement of collagen II cleavage [9], we found elevated concentrations of CPII. Increases in SF CPII levels have also been noted in human osteoarthritis and rheumatoid arthritis patients, as well as in animal models of osteoarthritis $[7,17,29]$. The increase in CPII following joint injury or with osteoarthritis development has generally been interpreted as a reparative response intended to mend damage to the collagen network. The current data indicate that a single transient inflammatory insult can also induce sustained changes in SF CPII levels over 1 week.

There are some limitations to the current study. The use of normal horses and a transient inflammatory stimulus may limit 
Figure 3
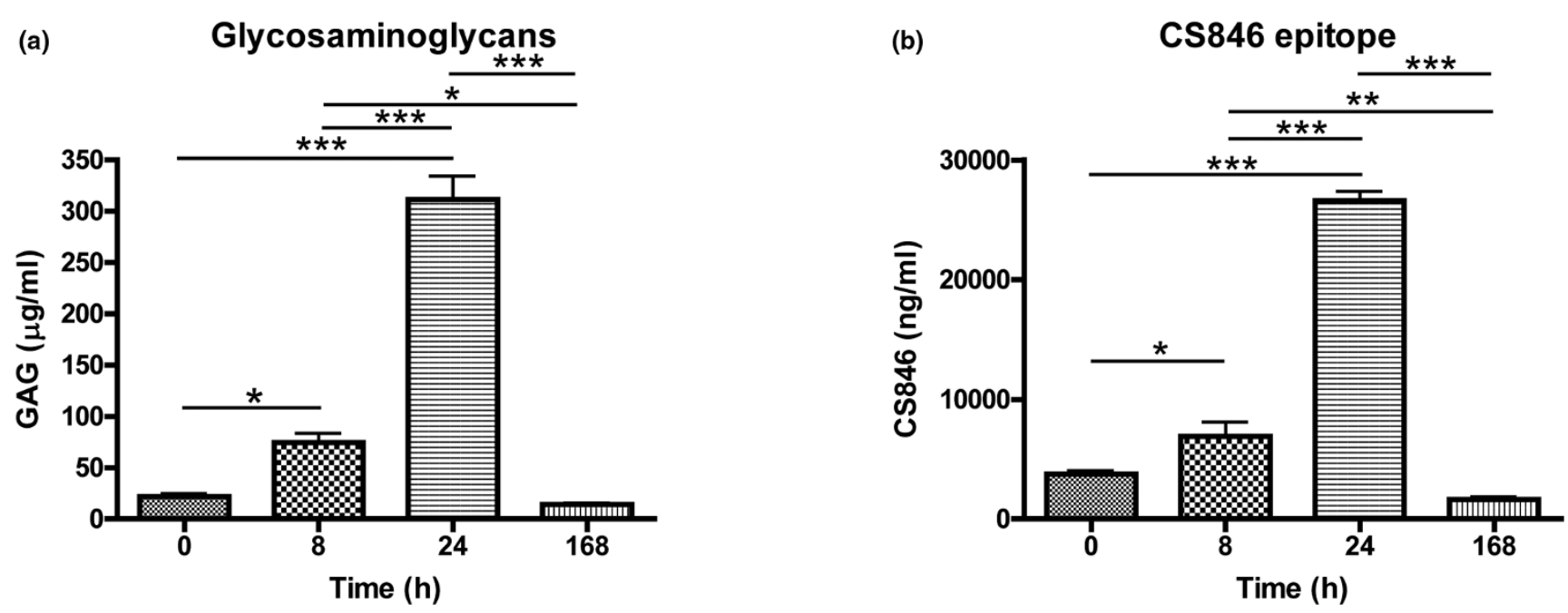

Synovial fluid levels of aggrecan turnover markers in inflamed joints. Synovial fluid concentrations of (a) glycosaminoglycans (GAG) and (b) chondroitin sulfate epitope 846 (CS846) over time in inflamed intercarpal joints of horses $(\mathrm{n}=6)$. Inflammation was induced at $t=0$ by intra-articular injection of $0.5 \mathrm{ng}$ Escherichia coli lipopolysaccharide. Data presented as the mean \pm standard error of the mean. ${ }^{\star} P<0.05,{ }^{* \star} P<0.01,{ }^{* \star *} P<$ 0.001 .

\section{Figure 4}

(a)

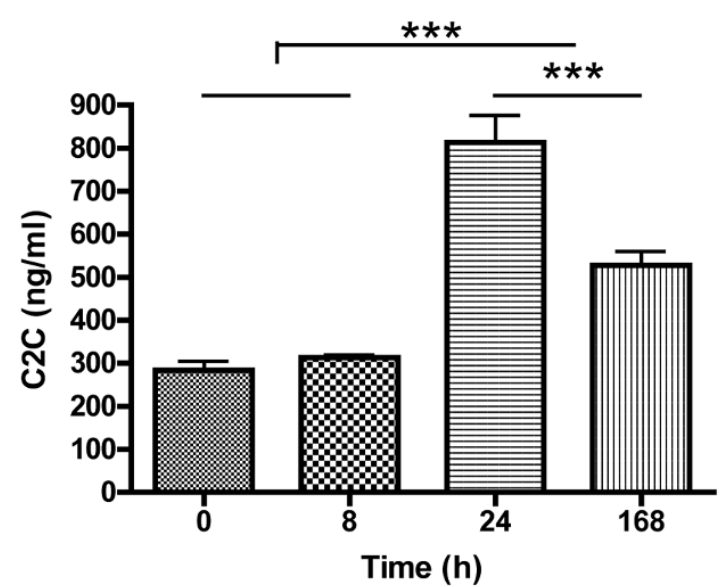

(b)

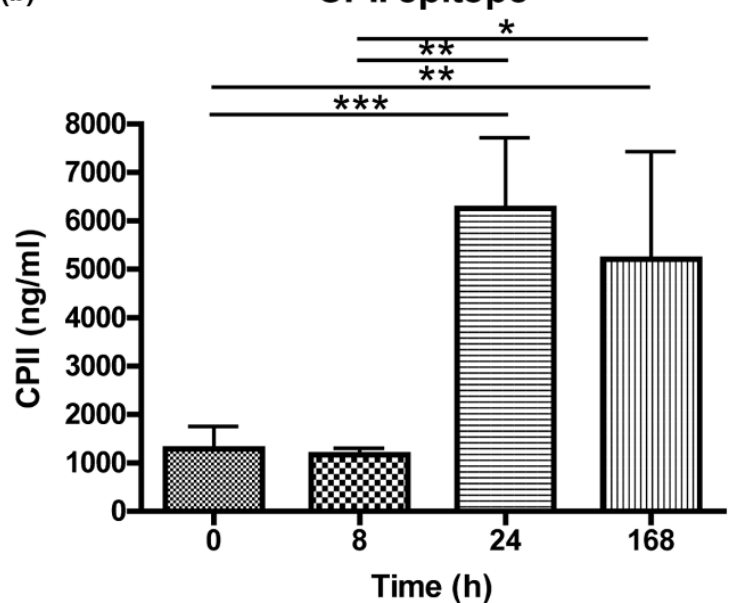

Synovial fluid levels of collagen II turnover markers in inflamed joints. Synovial fluid concentrations of (a) collagenase-cleavage neoepitope of type II collagen (C2C) and (b) carboxypropeptide of type II collagen epitope (CPII) over time in inflamed intercarpal joints of horses $(n=6)$. Inflammation was induced at $t=0$ by intra-articular injection of $0.5 \mathrm{ng}$ Escherichia coli lipopolysaccharide. Data presented as the mean \pm standard error of the mean. ${ }^{\star} P<0.05,{ }^{\star \star} P<0.01,{ }^{\star \star \star} P<0.001$.

extension of the results to diseased individuals with more chronic inflammation. The choice of the LPS model for induction of joint inflammation was based on it having been well studied in the horse $[19,21,22]$, showing reproducible local effects with accurate timing and quick recovery of joints. In addition, LPS is known to induce $\mathrm{IL}-1 \beta$ and various other cytokines and mediators, such as TNF $\alpha$ and prostaglandin $\mathrm{E}_{2}$, implicated in naturally occurring arthritis [34,42-44]. Injection of LPS (or any other inflammatory stimulus) into a joint will elicit a release of inflammatory mediators from both the synovial membrane and the articular cartilage, which may affect cartilage integrity and thus SF marker levels. Apart from this indirect pathway, a direct effect of LPS on chondrocyte gene transcription cannot be excluded. No discrimination can be made between both effects on SF markers, but any significant direct LPS effect can be considered very small, given the dosage used [22].

The lack of visualization of the articular cartilage unfortunately precludes a direct appreciation of the effects of LPS-induced 
inflammation on the cartilage in the current set-up. Sacrifice of horses and analysis of cartilage at PIH 168, however, was beyond the scope of the current study, especially as we expected changes in marker levels to have returned to baseline by this time. In retrospect, it would have been interesting to extend the period of inflammation and SF collection, and to include a direct evaluation of the articular cartilage at baseline as well as at study completion, since this would have allowed us to assess the predictive value of SF marker concentrations for the level of cartilage damage incurred.

No sham-injected contralateral joints were included in the current study for comparison of the effect of repeated arthrocentesis alone on SF marker levels versus the effect of LPS; however, multiple studies have previously shown the effects of LPS on SF parameters to far exceed that of saline injection, and thus probably that of arthrocentesis alone [19,34]. Lastly, $\mathrm{SF}$ marker concentrations reported here were not corrected for dilution effects due to joint effusion using blood:SF urea ratios as suggested previously [12]. As LPS produced consistent joint effusion, the reported rises in marker concentrations will be an underestimate rather than an overestimate, and hence the observed trends and validity of conclusions drawn will be unaffected by correction.

\section{Conclusions}

We have demonstrated pronounced effects of a single episode of joint inflammation on SF inflammatory mediators, MMP activity and cartilage biomarkers in healthy joints. In short, prostaglandin $E_{2}$, substance $P$, bradykinin and MMP activity rise shortly after induction of inflammation; both markers of aggrecan and collagen II turnover increase in response to transient inflammation; putative anabolic and catabolic markers for each of these matrix components rise simultaneously; and the rise in collagen II turnover markers occurs slightly later than that of aggrecan markers, and persists longer. While the extension of these data to the clinical situation requires caution given the above limitations of the current model, the present study shows that a single event producing significant intraarticular inflammation may have a prolonged effect on SF concentrations of markers of cartilage turnover.

\section{Competing interests}

The authors declare that they have no competing interests.

\section{Authors' contributions}

JCdG participated in the study design, carried out the experimental procedures, performed the mediator and marker (immuno)assays and drafted the manuscript. CHAvdL provided technical support with the synovial fluid analyses, performed the statistical analysis, and assisted in manuscript preparation. PRvW conceived of the study, participated in its design and coordination, and helped draft the manuscript. All authors read and approved the final manuscript.

\section{Acknowledgements}

The authors would like to indicate that the data presented in this manuscript are part of a larger study investigating the effects of oral administration of a nonsteroidal anti-inflammatory drug on synovial fluid inflammatory parameters and cartilage biomarkers in inflamed equine joints. That study was partly funded by Boehringer Ingelheim Vetmedica (Alkmaar, the Netherlands); however, the funding agreement explicitly covered only those data that were directly related to treatment effects of the nonsteroidal anti-inflammatory drug under investigation. The funding source of the overall study therefore has no relation to the data pre-

sented in the current manuscript. The authors would also like to express their sincere gratitude to Ms Marjory Pollak for her invaluable help in sample collection and storage.

\section{References}

1. Loeuille D, Chary-Valckenaere I, Champigneulle J, Rat AC, Toussaint F, Pinzano-Watrin A, Goebel JC, Mainard D, Blum A, Pourel $J$, Netter P, Gillet P: Macroscopic and microscopic features of synovial membrane inflammation in the osteoarthritic knee: correlating magnetic resonance imaging findings with disease severity. Arthritis Rheum 2005, 52:3492-3501.

2. Hill CL, Hunter DJ, Niu J, Clancy M, Guermazi A, Genant H, Gale D, Grainger A, Conaghan P, Felson DT: Synovitis detected on magnetic resonance imaging and its relation to pain and cartilage loss in knee osteoarthritis. Ann Rheum Dis 2007, 66:1599-1603.

3. Sutton S, Clutterbuck A, Harris P, Gent T, Freeman S, Foster N Barrett-Jolley R, Mobasheri A: The contribution of the synovium, synovial derived inflammatory cytokines and neuropeptides to the pathogenesis of osteoarthritis. Vet $J 2009,179: 10-24$.

4. Scott-Lennox JA, McLaughlin-Miley C, Lennox RD, Bohlig AM, Cutler BL, Yan C, Jaffe M: Stratification of flare intensity identifies placebo responders in a treatment efficacy trial of patients with osteoarthritis. Arthritis Rheum 2001, 44:1599-1607.

5. Bauer DC, Hunter DJ, Abramson SB, Attur M, Corr M, Felson D, Heinegard D, Jordan JM, Kepler TB, Lane NE, Saxne T, Tyree B, Kraus VB, Osteoarthritis Biomarkers Network: Classification of osteoarthritis biomarkers: a proposed approach. Osteoarthr Cartil 2006, 14:723-727.

6. Matyas JR, Atley L, lonescu M, Eyre DR, Poole AR: Analysis of cartilage biomarkers in the early phases of canine experimental osteoarthritis. Arthritis Rheum 2004, 50:543-552.

7. Lohmander LS, Yoshihara Y, Roos H, Kobayashi T, Yamada $\mathrm{H}$, Shinmei M: Procollagen II C-propeptide in joint fluid: changes in concentration with age, time after knee injury, and osteoarthritis. J Rheumatol 1996, 23:1765-1769.

8. Henrotin Y, Addison S, Kraus V, Deberg M: Type II collagen markers in osteoarthritis: what do they indicate? Curr Opin Rheumato/ 2007, 19:444-450.

9. Fraser A, Fearon U, Billinghurst RC, lonescu M, Reece R, Barwick $T$, Emery P, Poole AR, Veale DJ: Turnover of type II collagen and aggrecan in cartilage matrix at the onset of inflammatory arthritis in humans: relationship to mediators of systemic and local inflammation. Arthritis Rheum 2003, 48:3085-3095.

10. Ishiguro N, Ito T, Oguchi T, Kojima T, Iwata H, lonescu M, Poole AR: Relationships of matrix metalloproteinases and their inhibitors to cartilage proteoglycan and collagen turnover and inflammation as revealed by analyses of synovial fluids from patients with rheumatoid arthritis. Arthritis Rheum 2001, 44:2503-2511.

11. Myers SL, Brandt KD, Eilam O: Even low-grade synovitis significantly accelerates the clearance of protein from the canine knee. Implications for measurement of synovial fluid 'markers' of osteoarthritis. Arthritis Rheum 1995, 38:1085-1091.

12. Kraus VB, Huebner JL, Fink $C$, King JB, Brown S, Vail TP, Guilak F: Urea as a passive transport marker for arthritis biomarker studies. Arthritis Rheum 2002, 46:420-427.

13. Poole AR: An introduction to the pathophysiology of osteoarthritis. Front Biosci 1999, 4:D662-D670.

14. Garnero P, Delmas PD: Biomarkers in osteoarthritis. Curr Opin Rheumatol 2003, 15:641-646. 
15. Koch TG, Betts DH: Stem cell therapy for joint problems using the horse as a clinically relevant animal model. Expert Opin Biol Ther 2007, 7:1621-1626.

16. Laverty S, Sandy JD, Celeste C, Vachon $P$, Marier JF, Plaas $A H$ : Synovial fluid levels and serum pharmacokinetics in a large animal model following treatment with oral glucosamine at clinically relevant doses. Arthritis Rheum 2005, 52:181-191.

17. Frisbie DD, Ghivizzani SC, Robbins PD, Evans $\mathrm{CH}$, Mcllwraith CW: Treatment of experimental equine osteoarthritis by in vivo delivery of the equine interleukin-1 receptor antagonist gene. Gene Ther 2002, 9:12-20.

18. Mcllwraith CW: General pathobiology of the joint and response to injury. In Joint Disease in the Horse Edited by: Mcllwraith CW, Trotter GW. Philadelphia: W.B. Saunders; 1996:40-70.

19. Morton AJ, Campbell NB, Gayle JM, Redding WR, Blikslager AT: Preferential and non-selective cyclooxygenase inhibitors reduce inflammation during lipopolysaccharide-induced synovitis. Res Vet Sci 2005, 78:189-192.

20. Khumsap S, Lanovaz JL, Rosenstein DS, Byron C, Clayton HM: Effect of induced unilateral synovitis of distal intertarsal and tarsometatarsal joints on sagittal plane kinematics and kinetics of trotting horses. Am J Vet Res 2003, 64:1491-1495.

21. Meulyzer M, Vachon P, Beaudry F, Vinardell T, Richard H, Beauchamp G, Laverty S: Joint inflammation increases glucosamine levels attained in synovial fluid following oral administration of glucosamine hydrochloride. Osteoarthritis Cartilage 2009, 17:228-234.

22. Palmer JL, Bertone AL: Experimentally-induced synovitis as a model for acute synovitis in the horse. Equine Vet J 1994, 26:492-495.

23. Ross MW: The lameness score: quantification of lameness severity. In Diagnosis and Management of Lameness in the Horse Edited by: Ross MW, Dyson SJ. Philadelphia: W.B. Saunders; 2003:66-67.

24. Owens JG, Kamerling SG, Stanton SR, Keowen ML, PrescottMathews JS: Effects of pretreatment with ketoprofen and phenylbutazone on experimentally induced synovitis in horses. Am J Vet Res 1996, 57:866-874.

25. de Grauw JC, Brama PA, Wiemer $\mathrm{P}$, Brommer $\mathrm{H}$, Lest $\mathrm{CH}$ van de, van Weeren PR: Cartilage-derived biomarkers and lipid mediators of inflammation in horses with osteochondritis dissecans of the distal intermediate ridge of the tibia. Am J Vet Res 2006, 67:1156-1162.

26. Neumann U, Kubota H, Frei K, Ganu V, Leppert D: Characterization of Mca-Lys-Pro-Leu-Gly-Leu-Dpa-Ala-Arg- $\mathrm{NH}_{2}$, a fluorogenic substrate with increased specificity constants for collagenases and tumor necrosis factor converting enzyme. Anal Biochem 2004, 328:166-173.

27. Rizkalla G, Reiner A, Bogoch E, Poole AR: Studies of the articular cartilage proteoglycan aggrecan in health and osteoarthritis. Evidence for molecular heterogeneity and extensive molecular changes in disease. J Clin Invest 1992, 90:2268-2277.

28. Poole AR, lonescu M, Swan A, Dieppe PA: Changes in cartilage metabolism in arthritis are reflected by altered serum and synovial fluid levels of the cartilage proteoglycan aggrecan. Implications for pathogenesis. J Clin Invest 1994, 94:25-33.

29. Nelson F, Dahlberg L, Laverty S, Reiner A, Pidoux I, lonescu M, Fraser GL, Brooks E, Tanzer M, Rosenberg LC, Dieppe P, Poole AR: Evidence for altered synthesis of type II collagen in patients with osteoarthritis. J Clin Invest 1998, 102:2115-2125.

30. Kojima T, Mwale F, Yasuda T, Girard C, Poole AR, Laverty S: Early degradation of type IX and type II collagen with the onset of experimental inflammatory arthritis. Arthritis Rheum 2001, 44:120-127.

31. Song X, Zeng L, Jin W, Thompson J, Mizel DE, Lei K, Billinghurst RC, Poole AR, Wahl SM: Secretory leukocyte protease inhibitor suppresses the inflammation and joint damage of bacterial cell wall-induced arthritis. J Exp Med 1999, 190:535-542.

32. Frisbie DD, Ray CS, lonescu M, Poole AR, Chapman PL, Mcllwraith CW: Measurement of synovial fluid and serum concentrations of the $\mathbf{8 4 6}$ epitope of chondroitin sulfate and of carboxy propeptides of type II procollagen for diagnosis of osteochondral fragmentation in horses. Am J Vet Res 1999, 60:306-309.

33. Attur MG, Dave M, Akamatsu M, Katoh M, Amin AR: Osteoarthritis or osteoarthrosis: the definition of inflammation becomes a semantic issue in the genomic era of molecular medicine. Osteoarthr Cartil 2002, 10:1-4.

34. Hawkins DL, MacKay RJ, Gum GG, Colahan PT, Meyer JC: Effects of intra-articularly administered endotoxin on clinical signs of disease and synovial fluid tumor necrosis factor, interleukin 6 , and prostaglandin $\mathbf{E}_{\mathbf{2}}$ values in horses. Am J Vet Res 1993, 54:379-386.

35. Poole S, Lorenzetti BB, Cunha JM, Cunha FQ, Ferreira SH: Bradykinin $B 1$ and $B 2$ receptors, tumour necrosis factor alpha and inflammatory hyperalgesia. $B r J$ Pharmacol 1999, 126:649-656.

36. Ryu SY, Jeong KS, Yoon WK, Park SJ, Kang BN, Kim SH, Park BK, Cho SW: Somatostatin and substance $P$ induced in vivo by lipopolysaccharide and in peritoneal macrophages stimulated with lipopolysaccharide or interferon-gamma have differential effects on murine cytokine production. Neuroimmunomodulation 2000, 8:25-30.

37. Attur M, Al-Mussawir HE, Patel J, Kitay A, Dave M, Palmer G, Pillinger $\mathrm{MH}$, Abramson SB: Prostaglandin $\mathrm{E}_{2}$ exerts catabolic effects in osteoarthritis cartilage: evidence for signaling via the EP4 receptor. J Immuno/ 2008, 181:5082-5088.

38. Meini S, Maggi CA: Knee osteoarthritis: a role for bradykinin? Inflamm Res 2008, 57:351-361.

39. Chu Q, Lopez M, Hayashi K, lonescu M, Billinghurst RC, Johnson KA, Poole AR, Markel MD: Elevation of a collagenase generated type II collagen neoepitope and proteoglycan epitopes in synovial fluid following induction of joint instability in the dog. Osteoarthr Cartil 2002, 10:662-669.

40. Lohmander LS, lonescu M, Jugessur H, Poole AR: Changes in joint cartilage aggrecan after knee injury and in osteoarthritis. Arthritis Rheum 1999, 42:534-544.

41. Janusz MJ, Little CB, King LE, Hookfin EB, Brown KK, Heitmeyer SA, Caterson B, Poole AR, Taiwo YO: Detection of aggrecanase- and MMP-generated catabolic neoepitopes in the rat iodoacetate model of cartilage degeneration. Osteoarthr Cartil 2004, 12:720-728.

42. Todhunter PG, Kincaid SA, Todhunter RJ, Kammermann JR, Johnstone B, Baird AN, Hanson RR, Wright JM, Lin HC, Purohit RC: Immunohistochemical analysis of an equine model of synovitis-induced arthritis. Am J Vet Res 1996, 57:1080-1093.

43. Hawkins DL, Cargile JL, MacKay RJ, Broome TA, Skelley LA: Effect of tumor necrosis factor antibody on synovial fluid cytokine activities in equine antebrachiocarpal joints injected with endotoxin. Am J Vet Res 1995, 56:1292-1299.

44. Petrov R, MacDonald MH, Tesch AM, Benton HP: Inhibition of adenosine kinase attenuates interleukin-1- and lipopolysaccharide-induced alterations in articular cartilage metabolism. Osteoarthr Cartil 2005, 13:250-257. 